\title{
ETHICAL INFORMATION SECURITY IN A CROSS-CULTURAL ENVIRONMENT
}

\author{
K. L. Nance \\ Department of Mathematical Sciences \\ University of Alaska \\ Fairbanks, AK 99775-1110 U.S.A.
}

\author{
M. Strohmaier \\ Department of Communication \\ University of Alaska \\ Fairbanks, AK 99775-5680 U.S.A.
}

\begin{abstract}
As political and ideological barriers all over the world have been changing, opportunities for collaborative efforts between companies and organizations have abounded, requiring technological advancements to support these cooperative efforts. Although some of the technologies have long been available, only recently have the political climate and associated costs made certain classes of technology realizable for global communication. This increased availability has necessitated a reevaluation of current information security standards to enable the adjustment of standards to the new global environment. Collaborators from all countries need to learn about the types of technology available, and positive and negative issues surrounding their use for cross-cultural cooperative efforts. They must also participate in the development of a general information security protocol which protects all participants while at the same time creating a truly global community. This will enable the development of global systems which are both open to the intended audience and secure from unauthorized access.
\end{abstract}

\section{SECURITY ENVIRONMENTS}

"Barriers to the full flow of information loom today just as barriers to the development of the interstate highway system existed in the past [5]." The ongoing evolution of the Information Age has resulted in a spiraling relationship between information security concerns and solutions. On the negative side, the Information Age has brought about a deluge of new concerns with respect to information security. On a more positive note, the Information Age has provided the technological and ideological solutions to many of the same information security issues. These technical and ideological solutions in turn have brought about further concerns with respect to information security, thus confirming the spiraling nature of the relationship. One recent example of this relationship which is currently receiving media attention concerns electromagnetic waves. A report from the Japanese government indicates that the electromagnetic waves emanating from a PC could be intercepted by industrial and military spies for any number of uses. Calls have been made 
for research to determine methods for preventing spy activities and espionage [6]. This provides an excellent example of a Information Age problem which will require an Information Age solution. Although many security concerns are domain-specific, there exist generalized information security environments which relate in varying degrees to crosscultural computer-mediated communication (CMC). Investigation of these concerns and the affects which they have a cross-cultural CMC will bring about more effective and secure communications while enhancing information security. The security environments which must be addressed include the following: physical, personnel, network, software, hardware and regulatory [3].

\subsection{Physical Security Environment}

The first environment to be considered is the physical security environment, which includes the physical components an external entity may encounter in a system. The security building blocks which contribute to physical security include intrusion prevention, intrusion detection, environment protection, and disaster recovery [3]. When considered from a global perspective, the term physical security embodies many facets not traditionally included in this scope. With the erasure or deemphasizing of many of the physicality issues which previously dominated security situations, a new approach is required to protect a system from undesirable penetration. Prior to the establishment of the global community perspective, physical security was concerned with locations and physical barriers. The Information Age has diminished the impact of physical location on information security and increased crosscultural interaction. Consequently, there is now a need for an investigation of the impact this change has on the physical security environment building blocks.

Intrusion prevention activities will vary with working environment. In cultures where an organization's working environment is relatively private and space is an asset, the incorporation of a multiple barrier strategy will be fairly easy. Preventing others from having immediate proximity to the user will require no major cultural adaptations. This strategy can greatly reduce the possibility of physical security violations, while being perceived by the workers as an acceptable practice. In a culture where the spatial use is less generous, and therefore privacy is less possible or nonexistent, physical security violations pose a much greater difficulty. In such a culture, the act of secrecy involved in blocking another from one's work may be a violation of cultural tradition and practice. Although a multiple barrier strategy is possible in this case, it may not be acceptable to workers because it contradicts the cultural norm.

Intrusion detection could be accomplished through the computer itself, with a protocol to check and verify who had access to what. When combined with an employee log, this internal attempt to detect intrusion would work for most cultures. This act may be seen as being monitored by 'big brother,' but its reception would depend greatly on how it is introduced and explained to the employees and how it is managed.

The final two building blocks for this area are environment protection and disaster recovery. Environment protection is concerned with the physical environment and includes concerns such as weather, power, and natural disasters. Disaster recovery is concerned with minimizing the impact of a disaster, and includes backups and contingency plans. Since environment protection and disaster recovery are not concerned with personnel threats, these building blocks have not been greatly affected by the global community perspective. Thus, the increase in cross-cultural interaction has minimal impact in these areas. 


\subsection{Personnel Security Environment}

The second environment which must be addressed is personnel security. Prior to the Information Age, international security was quite a different story. In order to obtain "inside" information about a company, a subversive power needed to "plant" an agent in the organization or "turn" one of the existing personnel. With the decrease of the impact of physical locality on the ability of a subversive agency to penetrate a system, the need for an "insider" also decreased. Although, there is no doubt that the degree of penetration can be greatly enhanced by having a "mole," it is now possible to obtain much data which was previously available only within a limited physical proximity. The personnel security building blocks include interviews, background screening, training and monitoring [3].

Increased global communication and collaboration, brings with it increased competition. A person in the United States with a computer and the right skills can access another person in Japan for communication and collaboration; however, employee loyalty to groups and organizations vary from culture to culture. An employee for an American company, regardless of the loyalty they feel for their own work environment, probably feels little if any loyalty to the target company in Japan. In fact, group communication research suggests that the more cohesive a group environment, the more loyalty a member feels toward his or her group, and the more that person perceives an "us versus them" characteristic toward the "other." This may ease one's conscience, thereby enabling access to a foreign computer data base. A recent example of private information being obtained involves the Internet. There was a report of a hacker who easily found private telephone numbers for Queen Elizabeth and other high ranking British officials, secret addresses, and information concerning a secret communications station by obtaining unauthorized access to the database of British Telecom [6]. Today, a person in the United States with a computer and the right skills can access confidential company records in Japan, or almost any other country.

Although the Information Age has contributed greatly to the ability of an organization to conduct thorough background screening, the overall impact on interviews and training has been minimal. The final building block, monitoring, has been both enabled and necessitated by technological developments, with implications including transaction monitoring or physical observance of personnel behavior. The degree to which personnel accept monitoring will vary greatly with respect to culture.

\subsection{Regulatory Security Environment}

The final environment is regulatory security, the area most affected by the realization of a truly global community. The building blocks for regulatory security include laws, policies, procedures, and responsive actions [3]. Since the regulatory security environment is so dramatically affected by the perception of a global community, it follows that it represents one of the areas most dramatically impacted by cross-cultural concerns. Increased understanding of culture would be very beneficial in contributing to the development of regulations which can be effectively applied to a multitude of cultures.

There exists a cultures who will obey laws primarily because they are laws. Others require active enforcement or sanctions in order to respect a law, policy or ordinance. The role that culture plays in the reaction of an individual to laws or ordinances is very significant. Regarding authority acceptance, there are two dimensions that influence a culture's acceptance. First, authority exists in all cultures and societies as well as organizations. There are three basic patterns regarding orientation to authority: democratic, 
authority-centered and authoritarian [2]. A democratic orientation indicates that the person in the position of authority is expected to listen to the members and act upon the group's wishes for the good of the group. The authority-centered pattern revolves around a given structure or faith, and the commands issued are predictable as they are consistent with that structure or faith. If the authority figure deviates from the predictable direction, it is permissible to argue with that authority figure to point out the more appropriate command. Finally, the authoritarian orientation consists of a person in an authority position who may command whatever he/she desires; that instruction is to be followed without question--whether issued by the authority figure or some delegate.

The second dimension that points to a given culture's acceptance of authority comes from Hofstede's work [7]. Power distance is defined as "the extent to which the less powerful members of institutions and organizations accept that power is distributed unequally [8]." Cultures with a high level of power distance accept power, or authority, as a part of everyday society. This type of culture stresses the coercive and referent types of power because it is seen as a basic fact of life. Organizations in a high power distance culture have employees who are more directly and closely supervised, tend to avoid conflict with supervisors and have lower levels of trust for co-workers than those from lower power distance cultures. In contrast, lower level power distance cultures stress expert and legitimate types of power, and believe power should only be used when appropriate. Examples of high power distance cultures include Malaysia, Panama and Guatemala; examples of lower power distance cultures include Austria, Israel and Denmark.

\subsection{Other Security Environments}

The remaining three security environments identified include the network, software and hardware security environments. The security building blocks for network security include data encryption, dialup control, network controllers and fiber optics. The security building blocks for software security include access control, multilevel security, structured development and auditing. The security building blocks for hardware security include access control, reliability, electrical protection and hardware logic [3]. The degree to which the security concerns in this area are augmented by cross-cultural interaction is slight when compared with the other security environments. Security issues are frequently domain specific with special considerations required depending on the problem domain. Generalized classifications of the domains can group fields with similar information security issues. One such grouping can include financial institutions, scientific research, government, educational institutions and commercial businesses.

The degree to which the above concerns can be consolidated is highly dependent upon the field of concern. For example, the average company listed in the PREMIER 100, a listing of the 100 most effective users of information technology, has $20 \%$ of its workstations connected to suppliers or customers. For some companies, particularly in the financial services industry, linkage approaches $100 \%$ [9]. Thus, it becomes obvious that different domains have different security concerns. The major issues which need to be addressed by most domains include protecting a system from unauthorized access by competitors, access of economic information from government agencies, intentional fraud through illegal access, government intrusion on the rights of the individual and invasion of individual rights by the intelligence community [13]. A system must be protected from the aforementioned while still providing secrecy, integrity and availability to authorized parties. Some of these issues may be enhanced by the basic awareness of the impact of cultural differences on ethical 
behavior in a global community. Cultural issues become pronounced when individuals from differing cultures are required or choose to interact. The implications of the interaction need to be investigated as well as the impact of culture on defining ethical behavior.

\section{CROSS-CULTURAL COMMUNICATION}

Conformance with ethical behavior consists of adherence to the standards of conduct for any given group. When standards are not formalized, there can exist ethical disparity which results in many diverse problems. These problems can magnify the other issues of information security. Since the globally distinct individuals participating in a collaborative effort may be culturally and ethnically diverse, it is difficult to hold the individuals to a nonformalized set of standards. Several important issues need to be addressed in order to balance each individual's dual needs for freedom of expression and protection in the cyberspace. These issues include a general information security protocol for cross-cultural interaction and ethical accountability [11].

The most applicable of the technologies affecting information security in the global environment fall under the category of computer-mediated communication (CMC). Applications of CMC which could be implemented for the transfer of information between people of varying cultures include electronic mail (e-mail), distributed open systems and the currently evolving computer conferencing systems. E-mail allows direct communication between parties, regardless of geographical locations, in a one-to-one or one-to-many context. Although e-mail works quickly, it does not permit the immediacy of dialogue nor the nonverbal interaction accompanying face-to-face conversation. However, many companies consider electronic communications an increasingly popular route to reducing personnel costs and better integrating information into existing information systems [9]. Distributed open systems support cooperating distributed applications. Unfortunately, this makes them more susceptible to unauthorized access than a closed system. Computer conferencing systems facilitate group communication for geographically distinct groups, with participants contributing to input and receiving output, therefore simulating face-to-face interaction. Although computer conferencing systems vary greatly in their content and capabilities, they also limit the nonverbal components of interlocution.

These technologies introduce many exciting opportunities for collaboration between companies; however, there are certain confounding variables which need to be addressed in order for effective communication to occur, while still ensuring information security. Between individuals of different cultures, the major issues applicable to computer-mediated communication to be addressed include language barriers, nonverbal communication, overscrutinization, socialization and intimacy, and interpersonal synchrony. The major issues which affect information security are facework, respect, perception, and the varying cultural definitions of ethical behavior. "If a system is to be protected and secure, precautions must be instituted throughout it. A chain is only as strong as its weakest link [12]." Each of the following components can be seen as a link in the security chain.

\subsection{Human Language and Language Barriers}

Language does not merely refer to semantic differences, nor is it simply a set of arbitrary symbols through which ideas are transferred. "Language is a central influence on cultures 
and one of the most highly charged symbols of a culture [2]." Language helps to shape experiences and interpretations, as well as to enable them. Defining language generally involves references to the vocabulary, syntax and writing system of a culture.

There are obvious similarities as well as differences which become concerns when interactants have different primary languages. Some factors which may become paramount include the following: dealing with a second language in a primary mode, nuances and colloquial meanings may be lost, perceptual differences may hinder communication through interpretation and deciding which language to utilize in itself may prove problematic. Even the non-existence of certain words or their equivalents in some languages can leave gaps in the perceptual process. For example, the phrase "fair play" in English has no exact equivalent in many other languages. The Japanese have no word for "privacy" [2]. The absence of these concepts in certain languages may become significant.

A final confounding language factor comes from words or phrases that are common in one culture, but unknown in another. Those that come from games are the most obvious examples: "out in left field" is a phrase common to Americans from all socio-economic levels, yet there are many other cultures that would have no concept of what it means. Just as a "team player" may bring up images of sportsmanship in the United States, a "team player" may conjure up images of an integral worker in a business for a Japanese person.

\subsection{Nonverbal Communication}

Nonverbal communication is, in its simplest sense, communication without words, referring to body, facial and eye movements, space, territory, touch, use of environment and paralanguage (vocal rate, volume, and pausing), to name but a few. These aspects of communication other than words serve to accent, complement, contradict, regulate, repeat or even substitute for the verbal message. While research indicates that anywhere from $60 \%$ to $90 \%$ of communication is relayed through nonverbal channels with $\mathrm{CMC}$, there is little if any access to nonverbal communication.

There are five basic nonverbal communication functions, including the following: conveying interpersonal attitudes, expressing emotional states, managing conversations, exchanging rituals and regulating self-presentation [7]. These are all extremely important components in a working relationship, whether that relationship exists face-to-face or through CMC, regardless of if it is socially based or formed to reach some scientific goal.

What the nonverbal signals add to the establishment of a relationship is difficult to precisely measure, yet it is extremely important [1]. "Studies in teleconferencing have indicated that restricting the nonverbal channels has a great impact on relationships and procedural control [10]." Studies done in the late-seventies relied more heavily on media that involved vocal communication than does e-mail. Using the vocal channel media gives those involved the added dimension of paralanguage, indicating that e-mail communication is at a greater disadvantage than those utilized in the studies discussed.

\subsection{Overscrutinization}

In a face-to-face interaction, those involved react instantly to what is said. Given time and the variety of perceptions possible, the longer one has to interpret something that was said, the greater the number of variations occur. The ability to interpret something more than was meant into a message becomes much more prevalent when the message is on the screen or paper in front of the individual for an extended period of time. Where the spoken word is 
temporal, electronic mail is eternal, thus lending itself, even seeming to invite, reinterpretation.

\subsection{Socialization and Intimacy}

Cultures vary with regard to the rules or norms of socialization and intimacy. Socialization refers to the process by which an individual acquires the rules and norms of society [4]. This process of socialization also occurs in the formation of working groups and relationships in the determination of the rules and norms of that particular relationship. Participants from different cultures may have cultivated very unique perceptions of the acceptable level of intimacy in a relationship. They may also approach socialization in very different ways. Because there is always some degree of socialization before interactants can begin to progress toward any goal, the approach to socialization becomes important. The acceptable level of intimacy becomes crucial during the process of establishing what is and is not acceptable regarding topic discussion or level of personal questioning.

\subsection{Facework and Respect}

Face is "a projected image of one's self in a relational situation [7]." This image is constructed by all the interactants in a particular setting. For some cultures consistency, or the preservation of one's face, is crucial, as is the correspondence of the public self and private self. For other cultures, losing face has no associated negative impact. In the cultures where saving face is an important concern, there is a give-and-take reciprocal negotiation framework. Here, providing face-support for others further defines one's own face. Facework becomes important cross-culturally when a person from a culture that stresses face interacts with a person from a culture that does not. Comments chosen to transmit (or not), or allowances to help save-face for the other interactant (or lack thereof) could do more damage than can be repaired, even if no damage was intended."

The framework of face and saving face contributes to a system of mutual respect. In the most general sense, respect for any culture resides in the knowing and following of that culture's traditions, rules, and norms of behavior. Using facework as an example, if an individual's face is at stake, to respect their culture properly the other interactant would attempt to save-face for the individual---regardless of their own perception of the importance of this action. Awareness and acceptance of a culture's norms of behavior provide an important basis for information security. In order for an individual to respect the boundaries established by another, the individual must be aware of these boundaries whether implicit or explicit.

\subsection{Perception}

Perception refers to how an individual views input based on past experience and knowledge. This perception allows the individual to incorporate stimuli, both common and new, to allow for an appropriate response. On a simple level, perceptual inquiry investigates how identification of a particular item is possible. For instance, how do we know an "apple" is an "apple" and not an "orange?" On the more complex human level, perceptual research attempts to unravel such problems as how the brain translates the stationary flashing lights on a marquee into an illusion of motion, or how a person learns to interpret nonverbal communication. 
An individual is constantly bombarded with sensory stimuli. To allow the individual to function in a somewhat organized, less than chaotic manner, certain stimuli will be selected to be recognized and responded to, while others will be ignored. The stimuli most likely selected will be either novel, repeating, familiar or specific to some salient need of the individual. New stimuli catch one's attention and are more likely to be selected, as are repeating, flashy or brightly-colored stimulus material. Familiar stimuli are recognized in that they appease the individual's desire for affirmation. Finally, stimuli that are salient to an individual's needs will be noticed; for example, a thirsty person will respond to all stimuli that deal with liquids. A person in a new environment will search for stimulus materials that are similar to known perceptions. These similar stimuli will be used with less trepidation because the perceptual knowledge from past experience works as a guide. Once the new material is mastered, the individual will store the new information for future use.

The primary components of a perceptual base include an individual's background and past experiences. Given that no two individuals have exactly the same background and set of past experiences, no two individuals will perceive the same stimulus in exactly the same way. Likewise, since an individual's background is continually developing, the individual may not perceive one situation exactly the same way when encountering it a second time. Although some people do perceive more closely with one another, when considering cybernetics for a vast, heterogeneous audience, there will also be individuals who perceive in extremely different ways.

A cost-benefit ratio is generally used to determine the appropriateness of an item in a multitude of settings. In determining the cost-benefit ratio for any computer security system, for instance, there are many determinants which can be classified as intangible. Stemming from the discussion of perception, any two people will likely assign different importance to intangibles based on their culture, desires, past experiences, and personal likes and dislikes. Therefore, the cost-benefit ratios for such intangibles can vary greatly on an individual basis for the same items. Effective information security should consider the potential perceptions of outside individuals to increase the success of their security efforts.

\section{CALL FOR FUTURE INVESTIGATION}

Individuals from all cultures need to learn about the types of technology available, as well as information security concerns surrounding the use of their chosen technology. Investigation into the impact of multicultural variables on maintaining the security of computer information systems and applying that knowledge in the development of global regulations is a step toward eliminating the negative aspects of the global environment, leaving only the advantages. To presume that solutions could be expanded upon in this treatise is at best culturally insensitive, and at worst ethnocentric and arrogant. While the authors could certainly present solutions from their own cultural perspective, it is only with multi-faceted problem-solving in a multicultural context that true solutions can be presented. The importance of the issues broached, as well as the delicate nature of arriving at solutions, are brought out to ensure effectiveness in the stages of working toward secure global systems that are open to the intended audience and protected from unauthorized access. 


\section{REFERENCES}

[1] J.K. Brilhart. Effective Group Discussion. Wm. C. Brown, 1986.

[2] J.C. Condon \& F. Yousef. An Introduction to Intercultural Communication. MacMillan, 1985.

[3] J.A. Cooper. Computer \& Communications Security: Strategies for the 1990s. McGraw-Hill Book Company, 1989.

[4] J.A. DeVito. Human Communication: The Basic Course. Harper Collins, 1991.

[5] R.G. Ellis. "Intellectual Property Owners Require Just Compensation." Signal, October 1994, p. 17.

[6] R. Fox . "Newstrack." Communications of the ACM, January 1995, p. 10.

[7] W.B. Gudykunst \& S. Ting-Toomey. Culture and Interpersonal Communication. Sage, 1988.

[8] G. Hofstede and M. Bond. "Hofstede's culture dimensions: An independent validation using Rokeach's value survey." Journal of Cross-Cultural Psychology, 1984 (15), 417-433.

[9] A. Jenkins. “Get Connected!' Computerworld Premier 100, September 19, 1994, CW Publishing, Inc., 1994.

[10] R. Johansen, J. Valle, \& K. Spangler. Electronic Meetings: Technical Alternatives and Social Choices. Addison-Wesley, 1979, pp. 17-25.

[11] K.L. Nance \& M. Strohmaier, Ethical Accountability in the Cyberspace. Proceeding of the ACM Ethics in the Computer Age Conference., (In Press), 1994.

[12] A. Silberschatz \& P. B. Galvin. Operating System Concepts. Addison-Wesley, 1994, p. 65 .

[13] W. Stallings. Operating Systems. Macmillan Publishing Company, 1992. 